\title{
Cytoprotective activity of minocycline includes improvement of mitochondrial coupling: the importance of minocycline concentration and the presence of VDAC
}

\author{
Andonis Karachitos • Joaquin Jordan • Hanna Kmita
}

Received: 1 September 2011 / Accepted: 14 December 2011 / Published online: 11 May 2012

(C) The Author(s) 2012. This article is published with open access at Springerlink.com

\begin{abstract}
Available data indicate that minocycline, an antibiotic of the tetracycline family, has cytoprotective properties due to a direct interaction with mitochondria. Yet, the data in the case of isolated mitochondria suggest discrepant or even detrimental effect(s) of the interaction. We have studied the cytoprotective activity displayed by minocycline in the case of the yeast Saccharomyces cerevisiae cells pretreated with $\mathrm{H}_{2} \mathrm{O}_{2}$. We demonstrated that the activity of minocycline required the presence of VDAC (voltage-dependent anion-selective channel) and provided distinct improvement of mitochondrial coupling. In the case of isolated mitochondria, we verified that minocycline exhibited uncoupler activity when applied in micromolar concentrations. However, when added in nanomolar concentrations, minocycline was able to improve the level of coupling for isolated mitochondria. The coupling improvement effect was observed in mitochondria containing VDAC but not in $\Delta$ porl mitochondria (depleted of VDAC1, termed here VDAC) and in both types of mitoplasts. Thus, properly low concentrations of minocycline within the cell in the vicinity of VDAC-containing mitochondria enable the improvement of energy coupling of mitochondria that contributes to cytoprotective activity of minocycline.
\end{abstract}

\footnotetext{
A. Karachitos $\cdot$ H. Kmita $(\bowtie)$

Laboratory of Bioenergetics, Institute of Molecular Biology and Biotechnology, Faculty of Biology, Adam Mickiewicz University, Umultowska 89,

61-614 Poznań, Poland

e-mail:kmita@amu.edu.pl

J. Jordan

Neuropharmacology Group, Department of Medical Sciences, Albacete College of Medicine, University of Castilla-La Mancha, Albacete, Spain
}

Keywords Saccharomyces cerevisiae · Minocycline · Cytoprotection $\cdot$ Mitochondria $\cdot$ Energy coupling $\cdot$ VDAC

$\begin{array}{ll}\text { Abbreviations } \\ \text { FCCP } & \begin{array}{l}\text { Carbonyl cyanide p-trifluoromethoxy } \\ \text { phenylhydrazone }\end{array} \\ \text { state } 4 & \begin{array}{l}\text { Resting respiration in the absence of ATP } \\ \text { synthesis }\end{array} \\ \text { state U } & \begin{array}{l}\text { Uncoupled respiration in the presence of maximal } \\ \text { capacity through the electron transfer system }\end{array} \\ \text { TBT } & \begin{array}{l}\text { Tributylin } \\ \text { VDAC }\end{array} \\ \text { Voltage-dependent anion-selective channel }\end{array}$

\section{Introduction}

Minocycline, a derivative of tetracycline (7-dimethylamino6-dimethyl-6-deoxytetracycline), is an antibiotic displaying broad-spectrum antibacterial activity and commonly indicated in the treatment of diseases with an inflammatory background (e.g. Vandekerckhove et al. 1998). On the other hand, increasing data point toward cytoprotective properties of minocycline and its potential use in the treatment of different diseases. For example, there are more than 300 publications on minocycline-induced neuroprotection, including experimental models of human diseases and clinical trials (reviewed in, e.g. Kim and Suh 2009; Plane et al. 2010). Such investigations have included: Parkinson's disease (e.g. Abdel-Salam 2008; Lu et al. 2010), Alzheimer disease (e.g. Kreutzmann et al. 2010; Hashimoto 2011), fragile X syndrome (e.g. Paribello et al. 2010), multiple sclerosis (e.g. Fong et al. 2008; Chen et al. 2011), cerebral ischemia (e.g. Fagan et al. 2010; Gupta and Chauhan 2011) as well as spinal cord and traumatic brain injury (e.g. Wang 
et al. 2006; Hawryluk et al. 2008). It is concluded that the cytoprotective capability of minocycline results from its anti-inflammatory, anti-apoptotic, and antioxidant properties (e.g. Jordan et al. 2007; Plane et al. 2010). However, there are also data pointing towards detrimental effects of minocycline (e.g. Jackson et al. 2007; Matsukawa et al. 2009; Plane et al. 2010). Thus, a detailed description of cellular and molecular mechanism(s) triggered by minocycline appears to be current and important.

It is widely accepted that mitochondrial dysfunction contributes to cell death and mitochondria are an important target of cytoprotective drugs. Consequently, the effect of minocycline on isolated mitochondria is studied. However, the available data support a discrepant or even detrimental mechanism(s) of minocycline effect on mitochondria. For example, obtained results indicate that minocycline may cause the depletion of endogenous $\mathrm{Mg}^{2+}$ or or its chelating resulting in increased permeability of the inner membrane (Kupsch et al. 2009). It has been also shown that minocycline induce the mitochondrial permeability pore (MPP) that could result in mitochondrial swelling and/or disruption of their membrane integrity (Kupsch et al. 2009; Mansson et al. 2010). On the other hand, data shown by Gieseler et al. (2009) and Antonenko et al. (2010) indicate that minocycline prevents MPP activation because of a direct inhibitory interaction with MPP or due to dissipation of the inner membrane potential by ion channels formed by minocycline in the inner mitochondrial membrane, respectively. Minocycline could also result in MPP modulation by affecting the activity of the voltage-dependent anion-selective channel (VDAC) located in the outer membrane, as well as the mitochondrial respiratory chain at the level of complexes I and IV (Garcia-Martinez et al. 2010), adenine nucleotide translocase and mitochondrial ATP synthase (FernandezGomez et al. 2005).

The discrepancies in the proposed effects of minocycline on isolated mitochondria respiration could result from differences in the applied experimental conditions. Potential causes may involve the incubation media (Kupsch et al. 2009) as well as some details concerning the applied media such as the presence and concentration of EGTA, $\mathrm{Mg}^{2+}$ and BSA. Nevertheless, all of the explanations suggest changes of the inner membrane permeability as a direct or indirect consequence of minocycline interaction with mitochondria. Since this interaction affects bioenergetic functions of mitochondria, it is logical to compare the effect of minocycline on respiratory coupling in mitochondria both after isolation and in intact cells. Unfortunately, to the best of our knowledge, this type of study is lacking.

The yeast Saccharomyces cerevisiae has been proven to be a very useful model in studies concerning the status of energy coupling in intact cells and isolated mitochondria (Michejda et al. 1990). Moreover, evolutionary proximity of animals and fungi is reflected in the presence of homologous genes and proteins in S. cerevisiae and humans. Consequently, S. cerevisiae is often used for studying a variety of complex processes including apoptosis and cytoprotection. For example, it is known that $\mathrm{H}_{2} \mathrm{O}_{2}$ induces apoptosis in $S$. cerevisiae as well as in mammalian cells (Magherini et al. 2007). In addition, $S$. cerevisiae mitochondria express two VDAC isoforms (VDAC1 and VDAC2) of which only VDAC1, encoded by the POR1 gene, has been proven to form a channel with properties highly conserved in other species (Blachly-Dyson et al. 1997; Lee et al. 1998). The presence of only one channel-forming VDAC isoform in S. cerevisiae mitochondria simplifies studies of the channel. Accordingly, it has been recently shown that the minocycline cytoprotective effect depends on the presence of VDAC (Gałgańska et al. 2010), and minocycline modulates conductance of VDAC reconstituted in artificial membranes (Garcia-Martinez et al. 2010). Therefore, a detailed description of cellular and molecular mechanisms surrounding VDAC and triggered by minocycline appears to be timely and necessary.

We applied S. cerevisiae mutant depleted of VDAC1 (termed here VDAC) and the isogenic wild type to estimate the effect of minocycline on the status of energy coupling in intact cells as well as in isolated mitochondria and mitoplasts. We observed that in $S$. cerevisiae cells protected by minocycline the status of energy coupling is improved. In the case of isolated mitochondria the coupling improvement also occurred but in the presence of minocycline concentrations an order of magnitude lower than those applied for intact cells. We also revealed the crucial role of VDAC for the effect of minocycline on mitochondria. Thus, we confirmed that mitochondria are the target for cytoprotective activity of minocycline although it appears that minocycline concentration within cells should be strictly controlled.

\section{Materials and methods}

Yeast strains and culture conditions

The following Saccharomyces cerevisiae strains were used: the isogenic wild type M3 (MATa, lys2 his4 trp1 ade2 leu2 ura3) and VDAC1 (porin1)-depleted mutant M22-2 ( $\Delta$ porl) (Blachly-Dyson et al. 1997; Lee et al. 1998). Yeast cells were grown at $28{ }^{\circ} \mathrm{C}$ in YPG medium $(1 \%$ yeast extract, $2 \%$ peptone, $3 \%$ glycerol) at $\mathrm{pH} 5.5$. For cell viability assay and cell respiration measurements, wild type and $\Delta$ porl cells were grown to exponential phase (OD at $\lambda=546$ of $0.6-$ $0.7 \mathrm{OD}$ ). Then $10 \mathrm{mM} \mathrm{H}_{2} \mathrm{O}_{2}$ or FCCP (carbonyl cyanide ptrifluoromethoxyphenylhydrazone), $0.14 \mu \mathrm{M}$ for wild type and $0.2 \mu \mathrm{M}$ for $\Delta$ por 1 was added in the presence or absence of $100 \mu \mathrm{M}$ minocycline (Sigma-Aldrich) and the cells were collected after $3 \mathrm{~h}$. For isolation of mitochondria and 
mitoplasts, wild type and $\Delta$ por 1 cells were collected at exponential growth phase (OD at $\lambda=546$ of $0.9-1.1$ ).

Cell viability assay and cell preparation for respiration measurements

Wild type and $\Delta$ porl cell viability was measured by plating serial dilution of treated and untreated cells on YPG plates and growing up the cells at $28{ }^{\circ} \mathrm{C}$ for 4 days as previously described in detail (Gałgańska et al. 2010). For measurements of wild type and $\Delta$ porl cell respiration, the cells were washed three times in $50 \mathrm{mM}$ potassium citrate buffer, $\mathrm{pH} 4.5$ and then used for oxygen uptake measurements (Michejda et al. 1990).

Isolation of mitochondria and mitoplasts

Mitochondria were isolated according to the published procedure and mitoplasts were obtained by the swelling procedure (Daum et al. 1982). The estimation of the integrity of the outer membrane was based on the permeability of the membrane to the exogenous cytochrome c (Douce et al. 1984). The calculated mean values of the mitochondrial outer membrane intactness were $98.7 \%$ and $95.4 \%$ for wild type and $\Delta$ por 1 mitochondria, respectively, and $72.4 \%$ and $71.8 \%$ for wild type and $\Delta$ por 1 mitoplasts, respectively. The mitochondrial and mitoplast protein concentration was estimated using the Bradford method with BSA as a standard.

\section{Oxygen uptake measurements}

The rate of oxygen uptake was measured at $25^{\circ} \mathrm{C}$ in $1 \mathrm{ml}$ of an incubation medium in a water-thermostated incubation chamber with a computer-controlled Clark-type $\mathrm{O}_{2}$ electrode (Oxygraph, Hansatech, UK). In the case of cell respiration, wild type and $\Delta$ porl cells (about 3 OD units) were suspended in $50 \mathrm{mM}$ potassium citrate buffer, $\mathrm{pH}$ 4.5. To obtain actual (native) respiration (fluctuating between state 4 and state 3), $10 \mathrm{mM}$ ethanol was added as the respiratory substrate. State 4 and state $U$ were induced by addition of tributylin (TBT) and FCCP, respectively (Michejda et al. 1990). TBT inhibits mitochondrial ATPase, but when added in too high concentrations it can cause uncoupling as a side effect. Moreover, its effective concentration depends on the $\mathrm{pH}$ of an incubation medium. Therefore, the applied concentration of TBT (30uM) was verified experimentally. The optimal concentration of FCCP (an uncoupler) yielding the highest respiratory rate (maximal respiration) depended on the strain, i.e. $1.4 \mu \mathrm{M}$ for wild type and $2 \mu \mathrm{M}$ for $\Delta$ porl.

Measurements for isolated mitochondria and mitoplasts (about $0.7 \mathrm{mg}$ ) were performed in $1 \mathrm{ml}$ of the standard incubation medium containing $0.6 \mathrm{M}$ mannitol, $5 \mathrm{mM} \mathrm{KCl}$, $10 \mathrm{mM}$ Hepes pH 6.9, $10 \mathrm{mM} \mathrm{KH} \mathrm{PO}_{4}, 0.2 \%$ BSA (defatted), in the presence of $10 \mathrm{mM}$ ethanol or external NADH as the respiratory substrates. Due to differences in external NADH access to wild type and $\Delta$ por 1 mitochondria (Antos et al. 2001) 0.8 and $2.4 \mathrm{mM} \mathrm{NADH}$ were added, respectively. In the case of mitoplasts $0.8 \mathrm{mM}$ NADH was added. State 4 was obtained by addition of oligomycin $(2 \mu \mathrm{g}$ per $\mathrm{mg}$ of mitochondrial protein). Minocycline at a different concentration was added at state 4 , and then state $U$ was induced by addition of FCCP $(1.4 \mu \mathrm{M}$ for wild type and $2 \mu \mathrm{M}$ for $\Delta$ por 1$)$.

Calculation of FCCP uncoupling capacity and percentage of TBT-sensitive respiration (state 3 share) in maximal respiration

Uncoupling capacity of FCCP was calculated for wild type and $\Delta$ por 1 cells, as well as for their isolated mitochondria and mitoplasts. The parameter denotes the state $U$ to state 4 ratio and indicates the status of energy coupling in intact cells and isolated mitochondria and mitoplasts. The percentage of TBTsensitive respiration at maximal respiration was calculated for intact cells. The parameters were calculated as the ratio of (native respiration - state 4 ) to state $U$, and correspond to state 3 performance (i.e. state 3 share) at maximal cell respiration induced by the uncoupler FCCP. Thus, it indicates the status of energy coupling in intact cells. The statistical significance of the calculated parameters was evaluated by $t$-test.

Recordings of minocycline spectra

Minocycline spectra were determined according to Antonenko et al. (2010) at $25^{\circ} \mathrm{C}$ in $1 \mathrm{ml}$ of the standard incubation media applied in measurements of rates of oxygen uptake, using a UV 1602 Shimadzu spectrophotometer. The spectra were recorded in the presence of increasing concentrations of different respiratory substrates, i.e. external NADH, ethanol, and succinate. Because NADH concentrations higher than $160 \mu \mathrm{M}(\mathrm{OD}=1$ at $\lambda=340 \mathrm{~nm})$ have non-specific effects upon minocycline spectra, and to maintain minocycline to external $\mathrm{NADH}$ ratio applied in oxygen uptake measurements, lower concentration (one tenth) of minocycline (i.e. $10 \mu \mathrm{M}$ ) was applied in the presence of NADH. Minocycline spectra were also recorded in the presence of wild type and $\Delta$ porl mitochondria and mitoplasts ( $60 \mu \mathrm{g}$ per $\mathrm{ml}$ of incubation medium) with or without external NADH $(160 \mu \mathrm{M})$.

\section{Results}

In the presence of VDAC, minocycline diminishes the effect of $\mathrm{H}_{2} \mathrm{O}_{2}$ on respiration coupling in yeast cells

The study was performed to provide input to the understanding of the cytoprotective effect of minocycline. We have reported recently that VDAC1 (termed here VDAC) is 
important for cytoprotective activity of minocycline observed for exponentially growing $S$. cerevisiae cells exposed to $\mathrm{H}_{2} \mathrm{O}_{2}$ (Gałgańska et al. 2010). Figure 1a shows wild type and $\Delta$ por 1 cell viability, presented as a capability to grow in serial dilutions of the cells on YPG plates. It is clearly visible that the cell viability was distinctly affected by pretreatment with $10 \mathrm{mM} \mathrm{H} \mathrm{H}_{2} \mathrm{O}_{2}$. Wild type cell growth was observed up to 1:100 dilution, whereas $\Delta$ porl cells had significant growth only when undiluted. Minocycline did not change the capability of the studied cells to grow on YPG plates, and its cytoprotective effect after $\mathrm{H}_{2} \mathrm{O}_{2}$ pretreatment was clearly visible only for wild type cells. Since VDAC is a mitochondrial protein and mitochondria are regarded as a target of minocycline cytoprotective capability, we decided to further examine the rate of respiration in wild type and $\Delta$ por 1 cells under the studied conditions.

It is well known that the rate of cell respiration is controlled by the respiratory state of mitochondria which fluctuates between the resting state (state 4; low oxygen uptake, higher inner membrane potential) and the phosphorylating state (state 3; high oxygen uptake, lower inner membrane potential). Therefore actual (native) cell respiration oscillates between these two states. The real state 4 in cells can be imposed by inhibitors of adenine nucleotide translocase or ATP synthase able to cross the cell membrane. On the other hand, a maximal rate of oxygen uptake (uncoupled state, state U) can be induced by FCCP, collapsing the inner membrane potential. Calculations of both native and state 4 respiration percentage of maximal respiration can provide information about the degree of coupling in cell respiration (Michejda et al. 1990). A representative trace applied for further calculations is shown in Fig. 1b. Ethanol (diffusing freely across biological membranes) was applied as the respiratory substrate known to be oxidized by $S$. cerevisiae mitochondria (De Vries and Marres 1987). The real state 4 was enforced by tributylin (TBT), known to inhibit ATP synthase and to act effectively in the case of $S$. cerevisiae cells (Michejda et al. 1990). As shown in Fig. 1c, for control conditions wild type and $\Delta$ porl cells displayed the same degree of respiration coupling because the degree of native and state 4 oxygen uptake stimulation with FCCP (shown as their percentage in maximal respiration) is the same in principle. In the presence of minocycline, the degree of respiration coupling appeared to be slightly improved in the case of wild type (a slight increase of FCCP stimulation capability), but $\Delta$ porl cells showed only trace improvement. Pretreatment of wild type and $\Delta$ porl cells with $\mathrm{H}_{2} \mathrm{O}_{2}$ resulted in an increase in state 4 share in maximal respiration that denotes a decrease of state 3 and less sensitivity to FCCP uncoupling activity. Thus, clear deterioration of the degree of cellular respiration coupling occurred, much more pronounced in the case of $\Delta$ por 1 cells. In the presence of minocycline, the effect of $\mathrm{H}_{2} \mathrm{O}_{2}$ persisted in $\Delta$ porl cells but was distinctly diminished in the case of wild type cells. To further analyze the influence of $\mathrm{H}_{2} \mathrm{O}_{2}$ and minocycline on respiration coupling in wild type and $\Delta$ porl cells, we calculated the uncoupling capacity of FCCP (i.e. state U to state 4 ratio) and the percentage of TBT-sensitive respiration in maximal respiration (i.e. oxygen uptake corresponding to state 3 , termed also state 3 share in maximal respiration). As shown in Fig. 1d, minocycline added separately or together with $\mathrm{H}_{2} \mathrm{O}_{2}$ increased the uncoupling capacity of FCCP (i.e. improved respiratory coupling) for wild type cells, while for $\Delta$ porl cells minocycline did not affect the uncoupling capacity of FCCP in the presence of $\mathrm{H}_{2} \mathrm{O}_{2}$. Moreover, minocycline added separately or together with $\mathrm{H}_{2} \mathrm{O}_{2}$ increased state 3's share in maximal respiration for wild type cells, while in the case of $\Delta$ por 1 cells the effect was not observed (Fig. 1e). Thus, it can be concluded that in the case of $S$. cerevisiae cells exposed to $\mathrm{H}_{2} \mathrm{O}_{2}$, the cytoprotective activity of minocycline is mediated by VDAC and consists of an improvement of cellular respiration coupling. To confirm the hypothesis, we examined the effect of minocycline on cell respiration coupling in the case of wild type and $\Delta$ porl cells exposed to FCCP.

In the presence of VDAC minocycline protects yeast cells against FCCP-triggered uncoupling

To determine the effect of minocycline in the case of wild type and $\triangle$ por 1 cells exposed to FCCP, we again determined the percentage of native and state 4 oxygen uptake in maximal respiration (Fig. 2a) and calculated the uncoupling capacity of FCCP and percentage of TBT-sensitive oxygen uptake (i.e. state 3 share) in maximal respiration (Fig. $2 b$ and c, respectively). The studied cells were pretreated with FCCP at concentrations corresponding to $10 \%$ of the concentration causing maximal respiration, added separately or together with $100 \mu \mathrm{M}$ minocycline. During the oxygen uptake measurements, maximal respiration was triggered by reducing FCCP concentration by $10 \%$ to avoid unspecific inhibition caused by a FCCP overdose. It should be emphasized that pretreatment with the applied concentration of FCCP did not decrease cell survival in a statistically significant way.

Under control conditions, the percentage of native and state 4 oxygen uptake in maximal respiration was in principle the same for wild type and $\Delta$ porl cells, i.e. they displayed the same degree of respiration coupling (Fig. 2a). Pretreatment of wild type and $\triangle$ por 1 cells with FCCP resulted in deterioration of degree of cell respiration coupling, more pronounced in the case of $\Delta$ porl cells. We observed an increase in state 4's share in maximal respiration that denotes a decrease of state 3 and weaker sensitivity to FCCP uncoupling activity. In the presence of minocycline, the effect of FCCP was totally eliminated for wild type cells, but was only slightly decreased for $\Delta$ porl cells. These observations correlate with data 
A

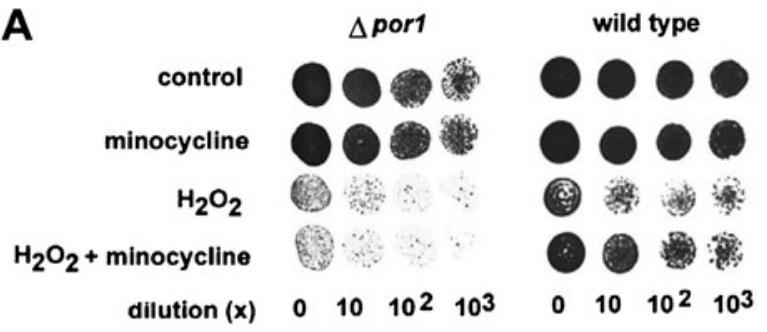

B

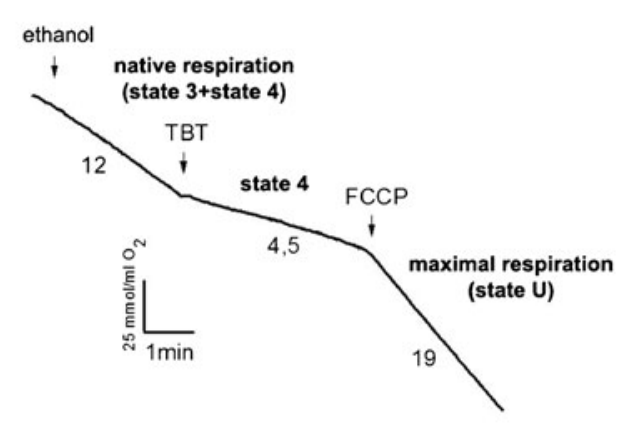

D

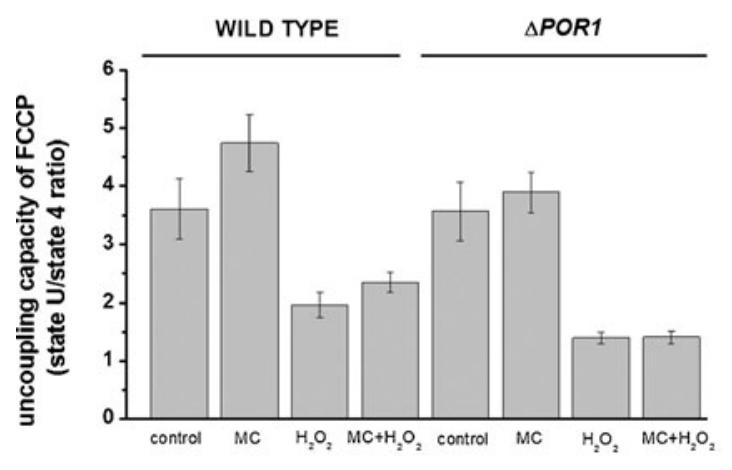

Fig. 1 Effect of minocycline on the status of energy coupling in wild type and $\Delta$ porl cells pretreated with $\mathrm{H}_{2} \mathrm{O}_{2}$. a Viability of wild type and $\Delta$ porl cells in the presence of $100 \mu \mathrm{M}$ minocycline applied separately or together with $10 \mathrm{mM} \mathrm{H}_{2} \mathrm{O}_{2}$. b Representative trace of measurements of the rate of oxygen uptake performed for wild type and $\Delta$ porl cells cultured in the presence of minocycline applied separately or together with $\mathrm{H}_{2} \mathrm{O}_{2}$. The trace explains respiratory states applied in further calculations. c Graphic presentation of state 4 and native respiration share in maximal respiration of the studied cells pretreated with minocycline applied separately or together with $\mathrm{H}_{2} \mathrm{O}_{2}$. Maximal respiration denotes the highest respiratory rate (state $\mathrm{U})$ revealed by FCCP. Values of FCCP uncoupling capacity $\mathbf{d}$ and percentage of TBT-sensitive respiration in maximal respiration (e)

concerning uncoupling capacity of FCCP and percentage of state 3 respiration in maximal respiration. As shown in Fig. 2b, pretreatment with FCCP decreased the state U to state 4 ratio, implying a decrease in the uncoupling capacity of FCCP, more efficiently in the case of $\Delta$ porl cells. Minocycline added together with FCCP distinctly increased the uncoupling capacity of FCCP in the case of wild type cells
C

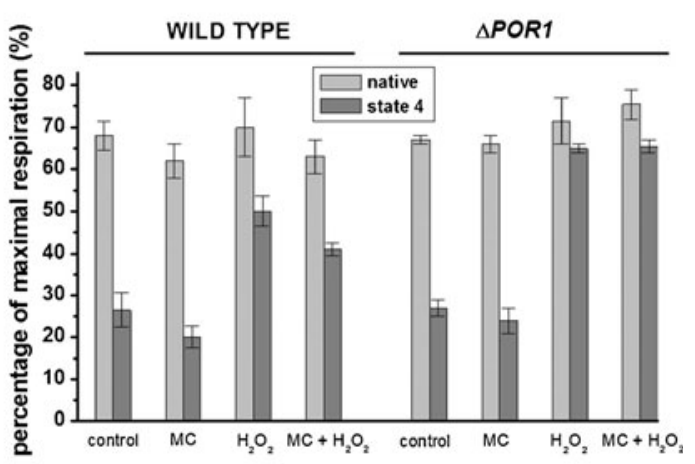

$\mathbf{E}$

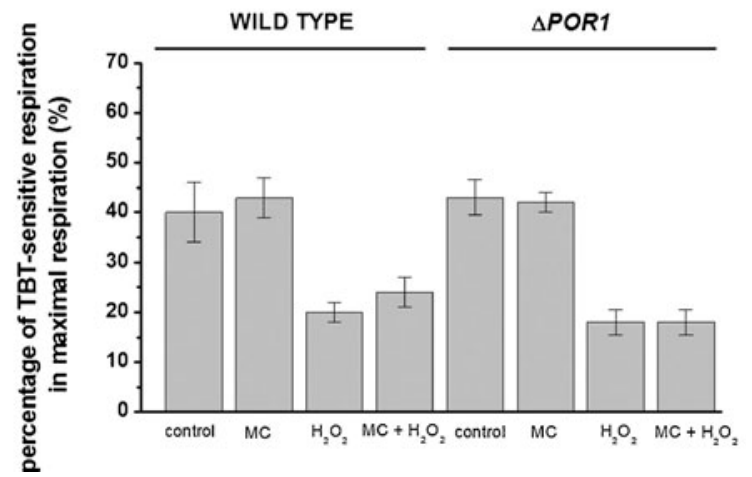

obtained for the studied cells pretreated with minocycline applied separately or together with $\mathrm{H}_{2} \mathrm{O}_{2}$. Uncoupling capacity of FCCP denotes state $U$ to state 4 ratio, while percentage of TBT-sensitive respiration in maximal respiration denotes the ratio of (native respiration - state 4) to state $U$ and corresponds to state 3 performance (i.e. state 3 share) in maximal cell respiration. The cell respiration was recorded in $50 \mathrm{mM}$ potassium citrate buffer, $\mathrm{pH} 4.5 .10 \mathrm{mM}$ ethanol was added as the respiratory substrate. State 4 was induced by addition of $30 \mu \mathrm{M}$ tributylin (TBT). The optimal concentration of FCCP yielding the highest respiratory rate (state $\mathrm{U}$ ) depended on the strain, i.e. $1.4 \mu \mathrm{M}$ for wild type and $2 \mu \mathrm{M}$ for $\Delta$ por 1 . Yeast colonies shown in a are typical results of three independent experiments. Data shown in c-e are mean values \pm SEM of four independent experiments

while $\Delta$ por 1 cells showed only slight improvement. Furthermore, in the case of wild type cells, minocycline added together with FCCP eliminated FCCP's effect on state 3's share in maximal respiration, but not for $\Delta$ porl cells (Fig. 2c). Thus, it can be concluded that in the case of $S$. cerevisiae cells containing VDAC, minocycline distinctly improves cellular respiration coupling. Therefore, we next studied whether 

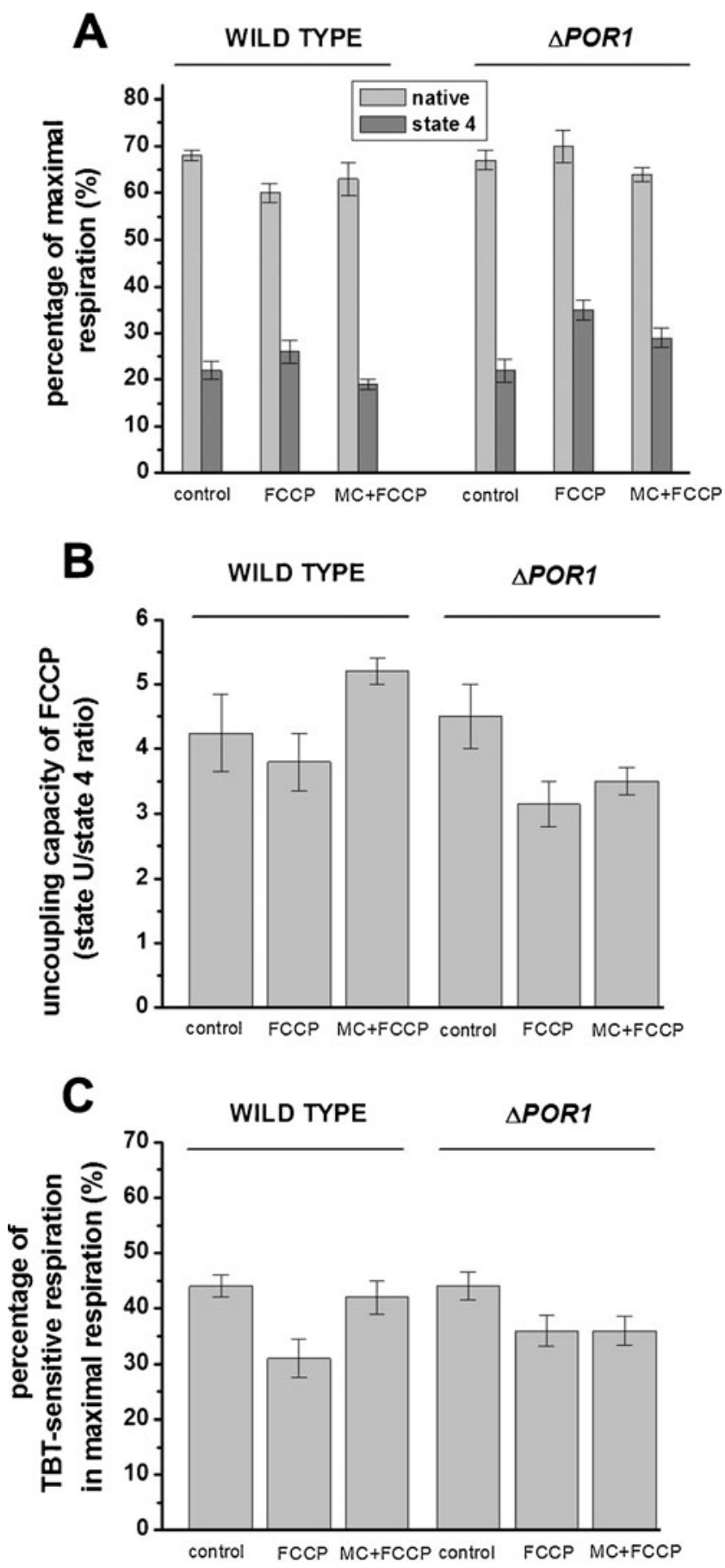

minocycline was able to improve coupling in the case of wild type and $\Delta$ porl isolated mitochondria.

The effect of minocycline on isolated mitochondria depends on its concentration and the presence of VDAC

Since the obtained results indicated that mitochondria participated in the cytoprotective effect of minocycline, we decided to check the effect of increasing concentrations of minocycline (up to $100 \mu \mathrm{M}$ ) on isolated wild type and
Fig. 2 Effect of minocycline on the status of energy coupling in wild type and $\Delta$ porl cells pretreated with FCCP. Measurements of the rate of oxygen uptake were performed as shown in Fig. 1b. The cells were pretreated with FCCP at concentration corresponding to $10 \%$ of the concentration causing maximal respiration $(0.14 \mu \mathrm{M}$ for wild type and $0.2 \mu \mathrm{M}$ for $\Delta$ por 1 ), added separately or together with minocycline. Maximal respiration denotes the highest respiratory rate (state $U$ ) revealed by FCCP. a Graphic presentation of state 4 and native respiration share in maximal respiration of the studied cells pretreated with FCCP applied separately or together with minocycline. Values of FCCP uncoupling capacity (b) and percentage of TBT-sensitive respiration in maximal respiration (c) obtained for the studied cells pretreated with FCCP applied separately or together with minocycline. Uncoupling capacity of FCCP denotes state $U$ to state 4 ratio while percentage of TBT-sensitive respiration in maximal respiration denotes the ratio of (native respiration - state 4) to state $U$ and corresponds to state 3 performance (i.e. state 3 share) in maximal cell respiration. The cell respiration was recorded in $50 \mathrm{mM}$ potassium citrate buffer, $\mathrm{pH}$ 4.5. $10 \mathrm{mM}$ ethanol was added as the respiratory substrate. State 4 was induced by addition of $30 \mu \mathrm{M}$ tributylin (TBT). The optimal concentration of FCCP yielding the highest respiratory rate (state U) depended on the strain, i.e. $1.26 \mu \mathrm{M}$ for wild type and $1.8 \mu \mathrm{M}$ for $\Delta$ porl. The data are mean values \pm SEM of three independent experiments

$\Delta$ porl mitochondria. VDAC appeared to be involved in the observed cytoprotective effect. Furthermore the permeability of the channel in S. cerevisiae mitochondria could be a limiting step in the transport of external NADH across the outer membrane (Antos et al. 2001). Therefore we chose external NADH and ethanol (known to diffuse freely across biological membranes) as the respiratory substrates and checked their oxidation also for mitoplasts. We also attempted to apply succinate but it was impossible to obtain effective state $U$ with the substrate, maybe because the electron transfer from succinate dehydrogenase (on the matrix face) to cytochrome $\mathrm{c}$ (on the cytoplasmic face) requires the presence of the inner membrane potential (Nicholls and Ferguson 2001). A representative trace applied for further calculations is shown in Fig. 3a. Minocycline, at different concentrations, was added at the real state 4 imposed by the addition of oligomycin, and FCCP was subsequently applied to estimate its uncoupling capacity. The FCCP uncoupling capacity denotes a state $U$ to state 4 ratio and indicates the status of energy coupling in mitochondria and mitoplasts. Therefore, the value of a quotient of the parameter determined in the presence and in the absence of minocycline less than 1 denotes a decrease in energy coupling, and a value greater than 1 denotes a higher energy coupling.

Minocycline concentrations in the range of $10-100 \mathrm{nM}$ and $10-100 \mu \mathrm{M}$ were applied. A reduced micromolar range of minocycline was investigated, as many research groups have already studied the effects of minocycline on isolated mitochondria at concentrations up to $100-200 \mu \mathrm{M}$ (e.g. Zhu et al. 2002; Cornet et al. 2004; Fernandez-Gomez et al. 2005; Kupsch et al. 2009; Antonenko et al. 2010; GarciaMartinez et al. 2010; Mansson et al. 2010). Since the concentrations might be difficult to obtain in vivo and some of the studies report their deleterious effects on energy 
A

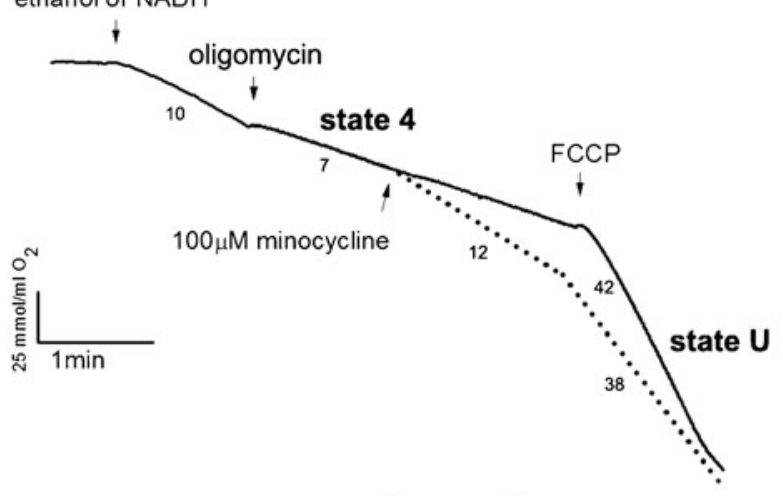

B

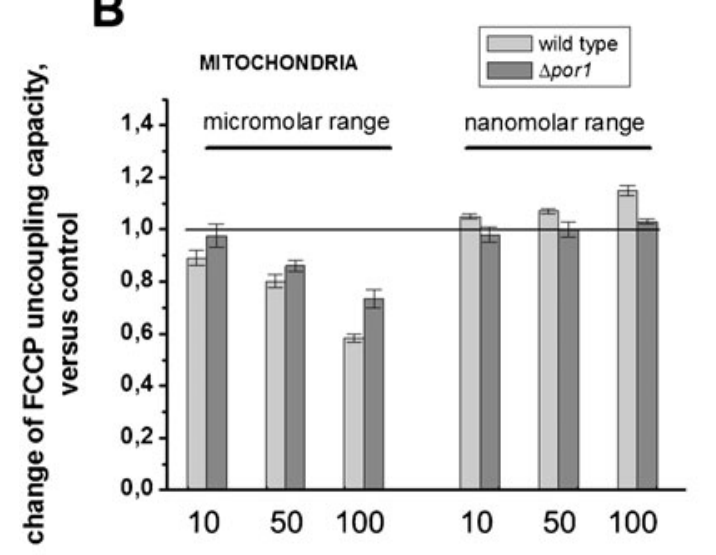

ethanol

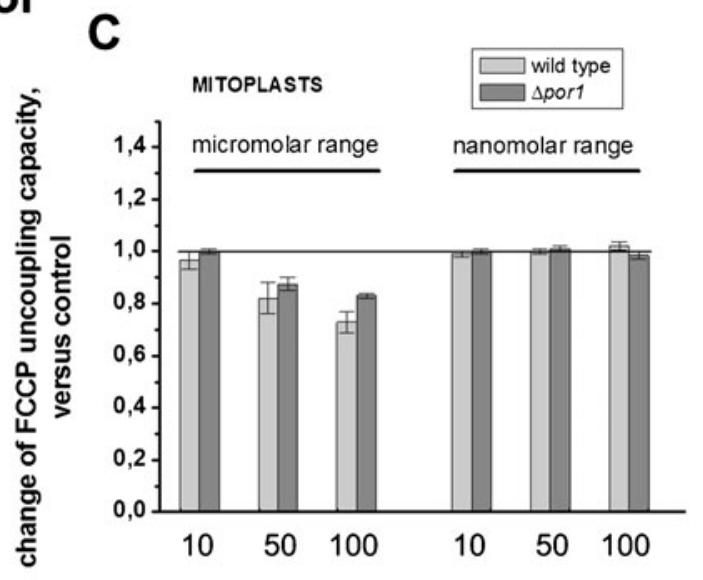

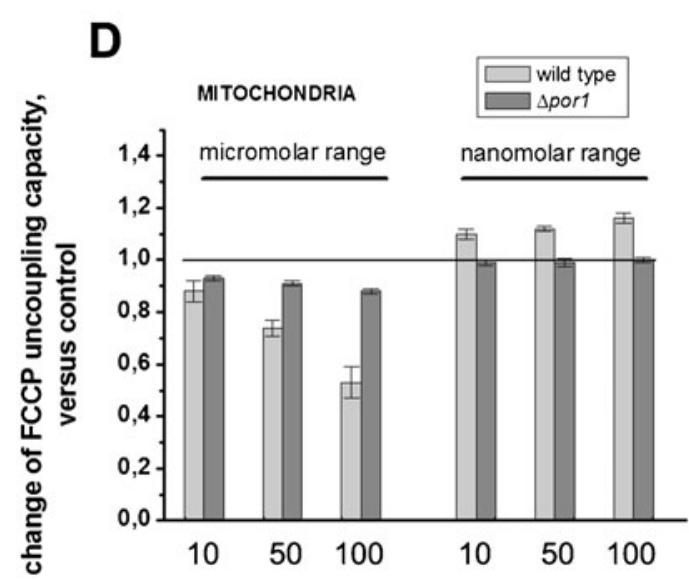

Fig. 3 Changes in FCCP uncoupling capacity for wild type and $\Delta$ porl mitochondria and mitoplasts incubated in the presence of micromolar and nanomolar ranges of minocycline concentrations. a Representative traces of measurements of the rate of oxygen uptake performed for wild type and $\Delta$ por 1 mitochondria and mitoplasts. The traces explain respiratory states applied in further calculations. The solid and dotted lines represent measurements performed in the absence and the presence of $100 \mu \mathrm{M}$ minocycline. Changes of FCCP uncoupling capacity as determined by state $U$ to state 4 ratio for wild type and $\Delta$ porl mitochondria in the presence of $10 \mathrm{mM}$ ethanol (b), wild type and $\Delta$ por 1 mitoplasts in the presence of $10 \mathrm{mM}$ ethanol (c),

coupling status, we also considered lower minocycline concentrations. In the micromolar range of minocycline

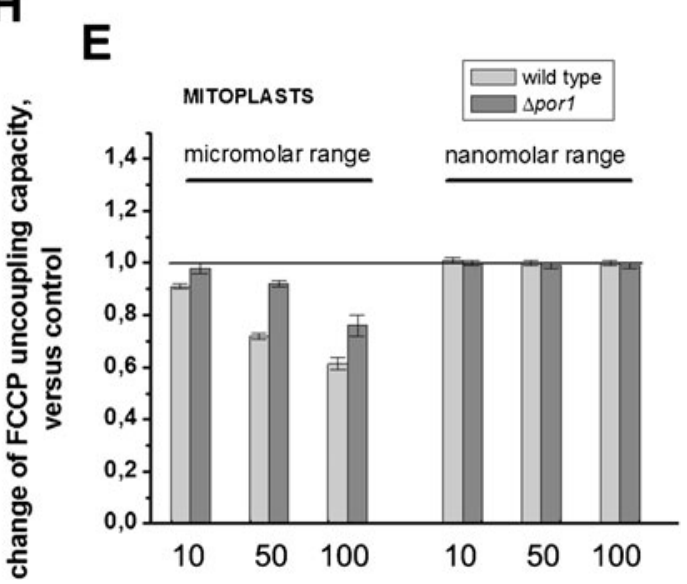

wild type and $\Delta$ por 1 mitochondria in the presence of 0.8 and $2.4 \mathrm{mM}$ external NADH, respectively (d) and wild type and $\Delta$ por 1 mitoplasts in the presence of $0.8 \mathrm{mM}$ external NADH (e). Measurements of oxygen uptake were performed in the standard incubation medium containing $0.6 \mathrm{M}$ mannitol, $5 \mathrm{mM} \mathrm{KCl}, 10 \mathrm{mM}$ Hepes $\mathrm{pH}$ 6.9, $10 \mathrm{mM} \mathrm{KH} \mathrm{PO}_{4}, 0.2 \%$ BSA (defatted), State 4 was obtained by addition of oligomycin ( $2 \mu \mathrm{g}$ per $\mathrm{mg}$ of mitochondrial protein) and state $\mathrm{U}$ by addition of 1.4 and $2 \mu \mathrm{M}$ FCCP for wild type and $\Delta$ porl, respectively. Minocycline concentration in the range of $10-100 \mathrm{nM}$ and $10-100 \mu \mathrm{M}$ was applied. The data are mean values \pm SEM of four independent experiments

concentration, we observed a decrease in energy coupling both in mitochondria from wild type and $\Delta$ porl cells 
(Fig. 3b, d) as well as in both types of mitoplasts (Fig. 3c, e). Nevertheless, some quantitative differences were observed for the minocycline effect dependent on the applied respiratory substrate and the type of mitochondria and mitoplasts. In the case of mitochondria, both in the presence of ethanol and external NADH, the effect of micromolar minocycline was distinctly stronger for wild type mitochondria. On the other hand, in the case of wild type mitochondria the effect of minocycline was comparable for both respiratory substrates while in the case of $\Delta$ porl mitochondria the effect of minocycline was more pronounced in the presence of ethanol. In the case of mitoplasts, the effect of micromolar minocycline was still substantially stronger for wild type than for $\Delta$ porl only in the presence of external NADH. However, the quantitative difference observed for the mitoplasts was distinctly weaker than that observed for the mitochondria. Interestingly, for both types of mitoplasts the effect of micromolar minocycline was comparable for ethanol and external NADH.

When minocycline was added in the nanomolar range, only wild type mitochondria exhibited an increase in energy coupling, independent of the applied respiratory substrate (Fig. 3b, d). For $\Delta$ porl mitochondria and both types of mitoplasts, the nanomolar range of minocycline did not change the status of energy coupling (Fig. 3b-e). Thus, low concentrations of minocycline (nM) may improve mitochondrial energy coupling in a VDAC-dependent way, whereas higher minocycline concentrations $(\mu \mathrm{M})$ appear to decrease mitochondrial energy coupling partly in a VDACindependent way. Consequently, one can conclude that a VDAC enables small amounts of minocycline to ameliorate energy coupling and the effect could be diminished in the absence of VDAC. Since alterations in minocycline spectrum are known to reflect its "functional state" (e.g. Antonenko et al. 2010) we decided to record minocycline spectra in the presence of different respiratory substrates as well as in the presence of wild type and $\Delta$ por 1 mitochondria and mitoplasts.

NADH influences the spectral properties of minocycline and the effect is diminished by VDAC

Since minocycline in the nanomolar range of concentration was able to improve energy coupling only in wild type mitochondria, i.e. in mitochondria containing VDAC and did not exert the effect in the case of mitoplasts we checked whether the absence of VDAC resulted in changes of minocycline properties. Therefore, we decided to obtain minocycline spectra under different conditions of incubation. First, minocycline spectra were recorded in the presence of different respiratory substrates: external NADH, ethanol, and succinate. As mentioned in Materials and Methods, the spectra were recorded for the micromolar range of minocycline concentration in the presence of increasing concentrations of these substrates. An unspecific effect of NADH concentrations higher than $160 \mu \mathrm{M}$ on minocycline spectra (not shown) forced us to apply concentrations one-tenth of the originally anticipated amount for both NADH and minocycline in order to maintain the quantitative ratio. The obtained results are shown in Fig. 4. Minocycline spectrum was distinctly changed in the presence of NADH (part a) whereas ethanol and succinate (part $\mathrm{b}$ and $\mathrm{c}$, respectively) did not influence the spectra. Thus, NADH is able to change properties of minocycline. Interestingly, ethanol oxidation by $S$. cerevisiae mitochondria is accounted for by a matrix-located alcohol dehydrogenase that oxidizes ethanol, resulting in reduction of matrix-located $\mathrm{NAD}^{+}$to $\mathrm{NADH}$, which is subsequently re-oxidized by the ethanol-dependent respiratory activity (Spencer et al. 1971; Boubekeur et al. 2001; Crichton et al. 2004). Therefore, in the presence of ethanol as the respiratory substrate, the interaction between minocycline and NADH (matrix-located) may occur. On the other hand, minocycline was not able to change the NADH spectrum (not shown).

To check the effect of VDAC's presence on minocycline spectral properties, we performed its spectra in the presence of wild type and $\Delta$ por 1 mitochondria and mitoplasts added separately or together with $160 \mu \mathrm{M} \mathrm{NADH}$. The effect of wild type mitochondria (Fig. 5a) on the analyzed spectra was distinctly different from those observed for both types of mitoplasts (Fig. 5b, d) and $\Delta$ porl mitochondria (Fig. 5c). After the addition of NADH, changes of minocycline spectra observed in the presence of both types of mitoplasts and $\Delta$ porl mitochondria were in principle the same and completely different from the spectrum observed in the presence of wild type mitochondria. Thus, it can be concluded that VDAC is able to preserve the form of minocycline important for improving the status of energy coupling of mitochondria.

\section{Discussion}

The presented results confirmed that the cytoprotective activity of minocycline includes its interaction with mitochondria. Moreover, the activity of minocycline appears to be mediated by VDAC and to consist of an improvement of cell respiration coupling. As shown for wild type and $\Delta$ por 1 cells of S. cerevisiae (Fig. 1), the extensive and fast response of their respiration to TBT imposing state 4 (inhibitor of ATP synthase) and to FCCP (uncoupler) are indicative of the tight coupling (Michejda et al. 1990). The calculated values of native and state 4 respiration share in maximal respiration as well as uncoupling capacity of FCCP (i.e. state $U$ to state 4 ratio) and percentage of TBT-sensitive respiration in maximal respiration (i.e. oxygen uptake 

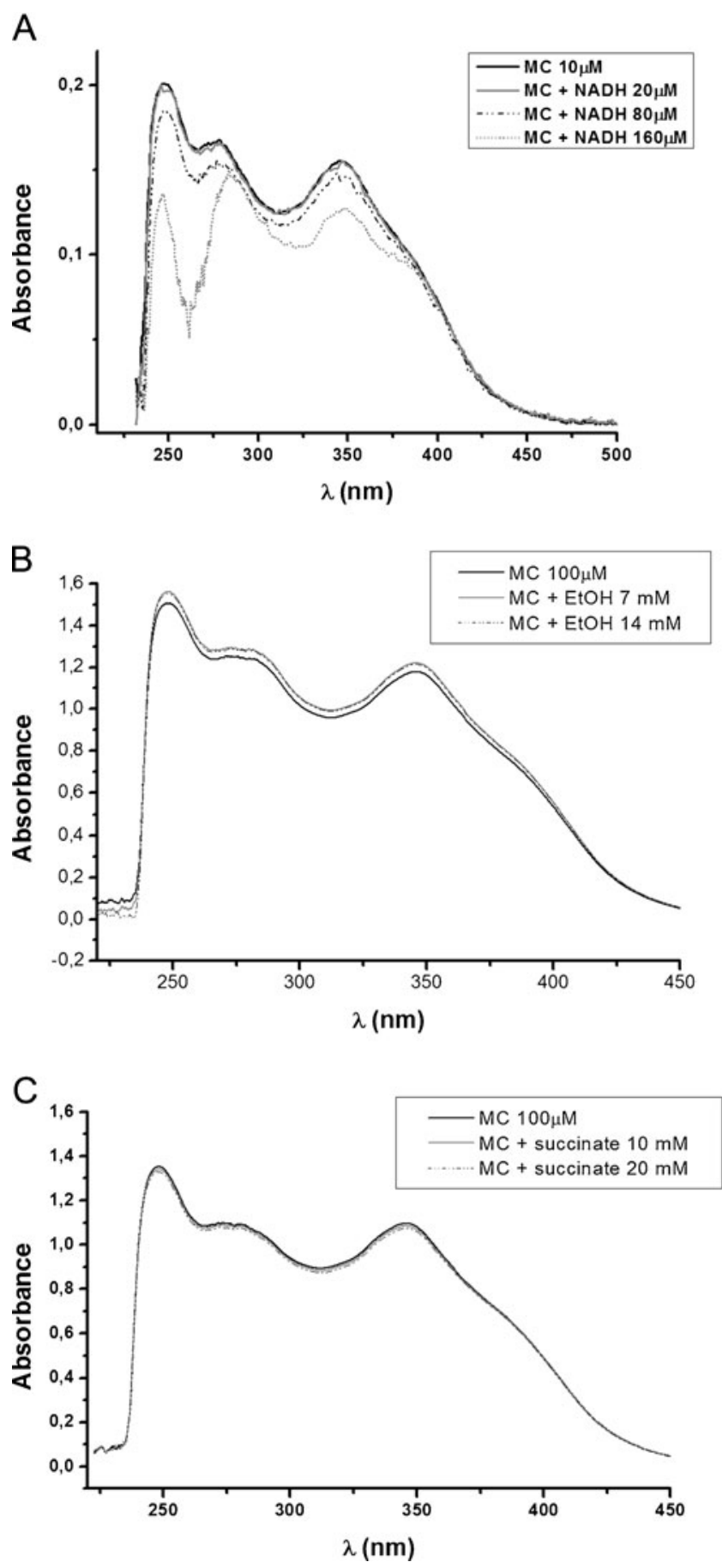

Fig. 4 Minocycline spectra in the presence of increasing concentrations of external NADH (a), ethanol (b) and succinate (c). The spectra were recorded according to Antonenko et al. (2010) in $1 \mathrm{ml}$ of the standard incubation media applied in measurements of rates of oxygen uptake at $25^{\circ} \mathrm{C}$, using UV 1602 Shimadzu spectrophotometer. Because of the unspecific effect of NADH concentrations higher than $160 \mu \mathrm{M}$ on minocycline spectra, and to maintain a minocycline to external NADH ratio applied in oxygen uptake measurements, one-tenth the concentration of minocycline $(10 \mu \mathrm{M})$ was applied in the presence of $\mathrm{NADH}$. The shown data are representative for four independent experiments corresponding to state 3 , termed also state 3 share in maximal respiration) were very similar. Pretreatment of these cells with $\mathrm{H}_{2} \mathrm{O}_{2}$ known to induce apoptosis both in S. cerevisiae and in mammalian cells (e.g. Gałgańska et al. 2010), resulted in clear deterioration of cell respiration coupling, much more pronounced in the case of $\Delta$ por 1 cells. The deterioration consisted of dramatic increases in state 4 respiration share in maximal respiration's, denoting a decrease of state 3 as well as weaker sensitivity to FCCP uncoupling activity. Consequently, the cell pretreatment with $\mathrm{H}_{2} \mathrm{O}_{2}$ decreased the uncoupling capacity of FCCP and state 3 's share in maximal respiration. However, the effect of $\mathrm{H}_{2} \mathrm{O}_{2}$ was distinctly diminished in the presence of minocycline for wild type cells, but still existed in $\Delta$ por 1 cells. In the case of wild type cells minocycline increased the uncoupling capacity of FCCP and state 3's share in maximal respiration and protected the cells against FCCP triggered uncoupling while the effects were not observed for $\Delta$ porl cells (Fig. 2). Thus cytoprotective activity of minocycline appears to result from an improvement of energy coupling within cells. Moreover, the effect of minocycline occurs in the presence of VDAC.

The above findings confirm that mitochondria are an important target of cytoprotective activity of minocycline. However, the obtained results indicate two contrary effects of minocycline on isolated mitochondria; a decrease and an increase in uncoupling as measured by calculation of changes of FCCP uncoupling capacity (Fig. 3). The dichotomous outcome depends on minocycline concentration. Minocycline displayed uncoupler activity when applied within a micromolar range of concentration, but it was able to improve the level of coupling when added within a nanomolar range of concentration. Interestingly, the coupling improvement effect was observed only in mitochondria containing VDAC, and not in $\triangle$ porl mitochondria or either type of mitoplasts. Thus, having as a reference our results shown in Figs. 1, 2 and 3, it can be concluded that minocycline within nanomolar concentrations is able to improve the level of energy coupling in VDAC-containing mitochondria. However, simultaneously the presence of VDAC in the outer mitochondrial membrane appears to be important for minocycline access into mitochondria, as well as for its uncoupling effect as shown for wild type and $\Delta$ porl mitochondria in the presence of ethanol. In contrast to external $\mathrm{NADH}$, ethanol diffuses freely across membranes and does not use VDAC to cross the outer membrane. Therefore, it can be speculated that VDAC may be involved in minocycline transport across the outer membrane as proposed by Cuenca-Lopez et al. (2011). Accordingly, it is known that minocycline is able to interact with VDAC (Garcia-Martinez et al. 2010). Therefore, it can be also suggested that minocycline interaction with VDAC results in changes of properties of minocycline and/or VDAC. 

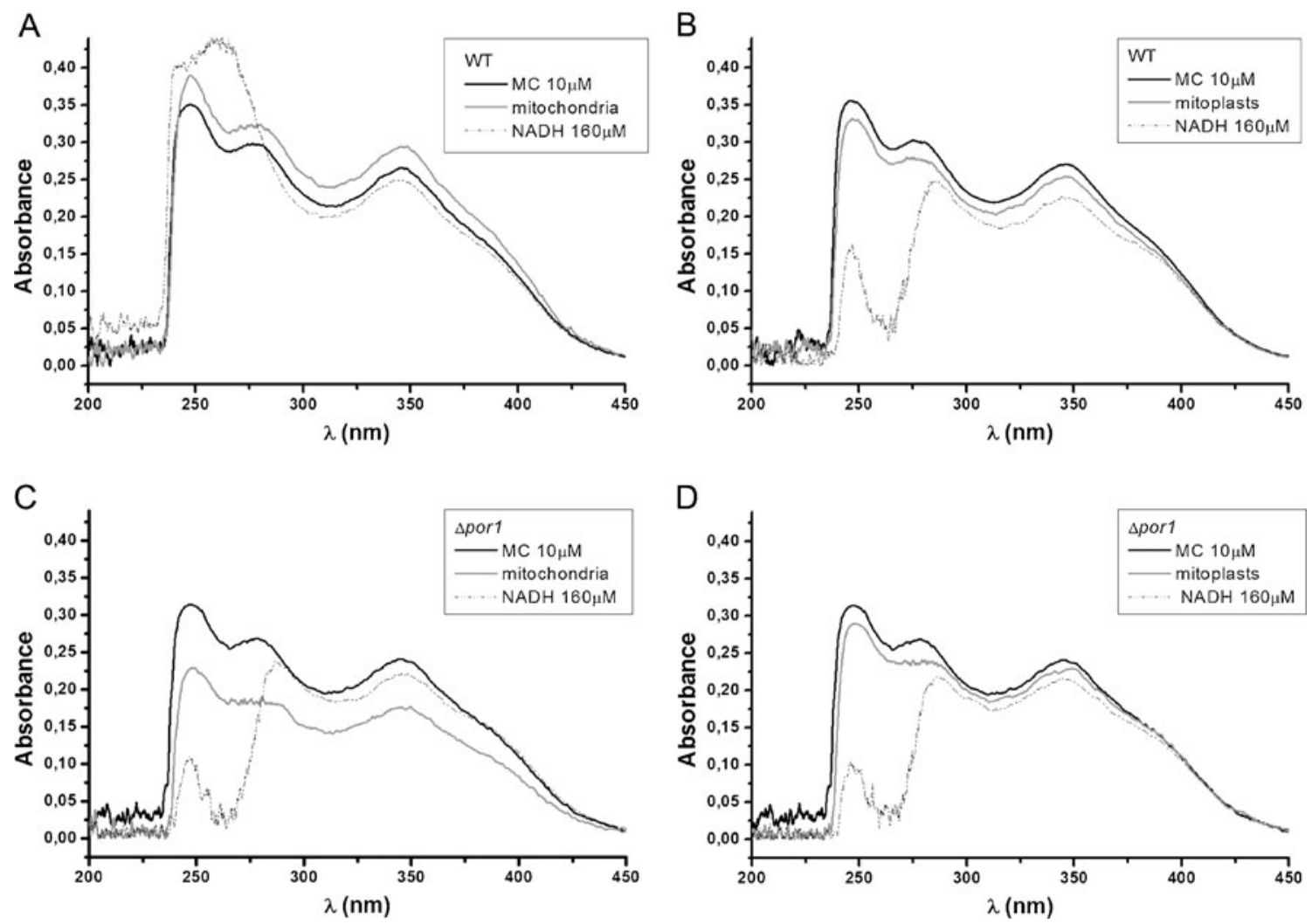

Fig. 5 Minocycline spectra in the presence of $160 \mu \mathrm{M}$ NADH and wild type mitochondria (a), wild type mitoplasts (b) $\Delta$ porl mitochondria (c) and $\Delta$ porl mitoplasts (d). The spectra were recorded as

described in the legend of Fig. 4 in the presence of $60 \mu \mathrm{g}$ of mitochondria and mitoplasts. The shown data are representative for four independent experiments

Changes in VDAC properties could cause modulation of metabolite traffic. However, the modulation would depend on minocycline concentration that denotes that interaction between VDAC and minocycline would depend on minocycline concentration. On the other hand, we observed that spectral properties of minocycline were affected by NADH (Fig. 4), and only wild type mitochondria were able to diminish changes of minocycline spectra imposed by NADH (Fig. 5). Moreover, minocycline at a nanomolar range of concentrations was able to improve the level of coupling only in the case of wild type mitochondria, but the effect was comparable for ethanol and external NADH (Fig. 3). Thus, it can be concluded that VDAC ensures nanomolar concentrations of minocycline to improve the level of mitochondrial coupling, protecting them from interaction with external and matrix-located NADH. Nonetheless, at micromolar concentrations, minocycline causes uncoupling although its small fraction can still interact with NADH and/or VDAC. It has been proven (Antonenko et al. 2010; Cuenca-Lopez et al. 2011) that minocycline is able to form ion channels in the inner mitochondrial membrane in the presence of the membrane potential. The channels result in increased ion permeability of the membrane leading to changes in the level of the

proton-motive force and energetic coupling. It can be assumed that minocycline concentration is important for the channel properties and subsequently for ion movement across the inner membrane. The question arises how minocycline passes through the barrier of the outer mitochondrial membrane. Our results indicate that besides VDAC, other mechanism(s) are possible. For example, the TOM complex channel may be involved as $\Delta$ porl mitochondria are still sensitive to minocycline. However, the sensitivity was distinctly weakened in the presence of external $\mathrm{NADH}$, which is known to be transported across the outer membrane by the TOM complex channel (Kmita and Budzińska 2000). Moreover, it cannot be excluded that, because of its lipid solubility, minocycline might also pass directly through the lipid bilayer, particularly at higher concentrations.

In conclusion, by using the simple model eukaryote, the yeast Saccharomyces cerevisiae and classical bioenergetic measurements, we confirmed that mitochondria are the target for the cytoprotective activity of minocycline. Moreover, the activity of minocycline requires the presence of VDAC, involves an improvement of the status of energy coupling in mitochondria, and depends on minocycline concentration. 
Open Access This article is distributed under the terms of the Creative Commons Attribution License which permits any use, distribution, and reproduction in any medium, provided the original author(s) and the source are credited.

\section{References}

Abdel-Salam OM (2008) CNS Neurol Disord Drug Targets 7:321-342 Antonenko YN, Rokitskaya TI, Cooper AJ, Krasnikov BF (2010) J Bioenerg Biomembr 42:151-163

Antos N, Stobienia O, Budzińska M, Kmita H (2001) J Bioenerg Biomembr 33:119-126

Blachly-Dyson E, Song J, Wolfgang WJ, Colombini M, Forte M (1997) Mol Cell Biol 17:5727-5738

Boubekeur S, Camougrand N, Bunoust O, Rigoulet M, Guerin B (2001) Eur J Biochem 268:5057-5065

Chen X, Ma X, Jiang Y, Pi R, Liu Y, Ma L (2011) J Neuroimmunol 235:1-8

Cornet S, Spinnewyn B, Delaflotte S, Charnet C, Roubert V, Favre C, Hider H, Chabrier PE, Auguet M (2004) Eur J Pharmacol 505:111-119

Crichton PG, Affourtit C, Moore AL (2004) Biochem J 401:459-464

Cuenca-Lopez MD, Karachitos A, Massarotto L, Oliveira PJ, Aguirre N, Galindo MF, Kmita H, Jordan J (2011) Pharm Res. doi:10.1016/j.phrs.2011.08.007

Daum G, Gasser SM, Schatz G (1982) J Biol Chem 257:13075-13080

De Vries S, Marres CA (1987) Biochim Biophys Acta 895:205-239

Douce R, Bourguignon R, Neuberger M (1984) Meth Enzymol 148:403-415

Fagan SC, Waller JL, Nichols FT, Edwards DJ, Pettigrew LC, Clark WM, Hall CE, Switzer JA, Ergul A, Hess DC (2010) Stroke 41:2283-2287

Fernandez-Gomez FJ, Galindo MF, Gomez-Lazaro M, González-García C, Ceña V, Aguirre N, Jordán J (2005) Neuroscience 133:959-967

Fong JS, Rae-Grant A, Huang D (2008) Recent Pat CNS Drug Discov 3:153-165

Gałgańska H, Karachitos A, Baranek M, Budzińska M, Jordán J, Kmita H (2010) Eur J Pharmacol 643:42-47

Garcia-Martinez EM, Sanz-Blasco S, Karachitos A, Bandez MJ, Fernandez-Gomez FJ, Perez-Alvarez S, de Mera RM, Jordan MJ, Aguirre N, Galindo MF, Villalobos C, Navarro A, Kmita H, Jordán J (2010) Biochem Pharmacol 79:239-250
Gieseler A, Schultze AT, Kupsch K, Haroon MF, Wolf G, Siemen D, Kreutzmann P (2009) Biochem Pharmacol 77:888-896

Gupta YK, Chauhan A (2011) Indian J Med Res 133:15-26

Hashimoto K (2011) Ann Neurol 69:739

Hawryluk GW, Rowland J, Kwon BK, Fehlings MG (2008) Neurosurg Focus 25:E14

Jackson AC, Scott CA, Owen J, Weli SC, Rossiter JP (2007) J Virol 81:6248-6253

Jordan J, Fernandez-Gomez FJ, Ramos M, Ikuta I, Aguirre N, Galindo MF (2007) Curr Drug Deliv 4:225-231

Kim HS, Suh YH (2009) Behav Brain Res 196:168-179

Kmita H, Budzińska M (2000) Biochim Biophys Acta 1509:86-94

Kreutzmann P, Wolf G, Kupsch K (2010) Cell Mol Neurobiol 30:979_ 984

Kupsch K, Hertel S, Kreutzmann P, Wolf G, Wallesch CW, Siemen D, Schönfeld P (2009) FEBS J 276:1729-1738

Lee AC, Xu X, Blachly-Dyson E, Forte M, Colombini M (1998) J Membr Biol 161:173-181

Lu L, Li F, Wang X (2010) CNS Neurol Disord Drug Targets 9:232240

Magherini F, Tani C, Gamberi T, Caselli A, Bianchi L, Bini L, Modesti A (2007) Proteomics 7:1434-1445

Mansson R, Morota S, Hansson MJ, Sonoda I, Yasuda Y, Shimazu M, Sugiura A, Yanagi S, Miura H, Uchino H, Elmér E (2010) Hepatology 51:347-348

Matsukawa N, Yasuhara T, Hara K, Xu L, Maki M, Yu G, Kaneko Y, Ojika K, Hess DC, Borlongan CV (2009) BMC Neurosci 10:126

Michejda J, Guo XJ, Lauquin GJ (1990) Biochem Biophys Res Commun 171:354-361

Nicholls DG, Ferguson SF (2001) Bioenergetics 3. Academic, London

Paribello C, Tao L, Folino A, Berry-Kravis E, Tranfaglia M, Ethell IM, Ethell DW (2010) BMC Neurol 10:91

Plane JM, Shen Y, Pleasure DE, Deng W (2010) Arch Neurol 67:1442-1448

Spencer C, Symons SA, Brunt RV (1971) Arch Mikrobiol 75:246-259

Vandekerckhove BN, Quirynen M, van Steenberghe D (1998) J Clin Periodontol 25:964-968

Wang KK, Larner SF, Robinson G, Hayes RL (2006) Curr Opin Neurol 19:514-519

Zhu S, Stavrovskaya IG, Drozda M, Kim BY, Ona V, Li M, Sarang S, Liu AS, Hartley DM, Wu DC, Gullans S, Ferrante RJ, Przedborski S, Kristal BS, Friedlander RM (2002) Nature 417:74-78 